\title{
REFINO DE ÓLEOS VEGETAIS UTILIZANDO LAVAGEM ÁCIDA COM RECIRCULAÇÃO
}

\author{
Eduardo Rasi de Almeida Prado ${ }^{1}$ \\ Flávio Luis Lemos ${ }^{I}$ \\ Ivan Lara $^{2}$ \\ Eduan de Oliveira Claro ${ }^{2}$ \\ Luiz Mario de Matos Jorge ${ }^{3}$
}

Resumo: O refino tradicional do óleo de soja consiste em submeter o produto às etapas de degomagem, neutralização, branqueamento e desodorização, buscando a melhoria de sua aparência física, odor e sabor. Cada uma destas etapas impacta consideravelmente sobre a qualidade e custo do óleo, sendo muitas vezes fator decisivo na competitividade global. Neste contexto, visando minimizar perdas, o trabalho teve enfoque na lavagem do óleo neutro, processo na qual ocorre na etapa de neutralização. Nos processos tradicionais, a neutralização dos ácidos graxos livres ocorre de forma alcalina com adição de hidróxido de sódio, a saponificação residual desta reação deve ser removida no processo seguinte que é a lavagem do óleo neutro. O presente estudo analisou a viabilidade da substituição do processo de lavagem com água pelo processo de lavagem ácida com recirculação, verificando as reduções nas perdas por arraste que ocorrem nas centrífugas de lavagem bem como a redução no consumo de água. Primeiramente, realizou-se um balanço de massa nas correntes de interesse. Posteriormente foram realizadas análises do teor de óleo contido nessas linhas mediante o processo de lavagem com água e o processo proposto, bem como a quantificação do consumo de ácido fosfórico utilizado durante os experimentos. Através dos resultados obtidos, verificou-se que o processo de lavagem ácida reduziu o teor de óleo presente na água residual em média de 2,5\% para 0,61\%, com a recirculação, foi possível abaixar o consumo de água desmineralizada em até $55 \%$ e reduzir o volume de carga contaminante enviada à planta de tratamento em até 44,5\%.

Palavras-chave: refino de óleo de soja, neutralização, lavagem ácida, recirculação de água.

\begin{abstract}
The traditional soybean oil refining process consists of submitting the product to degumming stage, neutralization, bleaching and deodorization, looking for improvement in their physic appearance, smell and flavor. This report had focused on neutralization, step which the washing of neutral oil occurs. In general, all chemical neutralization installations are equipped with at least one or often two washing steps. The purpose of washing the oil is to reduce the residual soap contained after neutralization with caustic soda. This study aimed to analyze the feasibility of replacing the current process of washing with water by an acid washing with recirculation, verifying reductions in drag losses that occur in washing centrifugal and there duction in water consumption. Firstly, the layout of the facility was assessed and carried out a mass balance in the current so finterest. Later, analysis was performed of the oil content contained in the selines by the current process and the proposed process, as well as the consumption of phosphoric acid used during the experiments. By the results obtained, it was found that the acid washing process with recirculation reduced the oil content present in the residual water averaged $2.5 \%$ to $0.61 \%$. It was also observed that with recirculation, it is possible to reduce the consumption of demineralized water up to $55 \%$ and reduce the amount of contaminant load sent to the treat ment plant (effluent) by 44,5\% compared with the current values. It was also found that the

${ }^{1}$ Programa de Pós-graduação em Engenharia Química da Universidade Estadual de Maringá - UEM. E-mail: dudarasi@yahoo.com.br; flavioluislemos@yahoo.com.br

${ }^{2}$ Engenharia Química da Universidade Estadual de Maringá - UEM. E-mail: ivanlara@hotmail.com; eduanclaro@gmail.com

${ }^{3}$ Engenharia Química da Universidade Estadual de Maringá - UEM. E-mail: lmmj@ deq.uem.br
\end{abstract}

ENGEVISTA, V. 16, n. 3, p.384-391, Setembro 2014 
acid washing process is economically viable, once there placement of the process, as proposed, will generate na additional profit to the plant, evidencing the effectiveness of the proposed modification.

Keywords: soybean oil refining, acid washing, neutralization, water recirculation.

\section{INTRODUÇÃO}

O Brasil é responsável por cerca de $28 \%$ da produção mundial de soja, é o segundo maior produtor e exportador mundial de soja em grão, farelo e óleo de soja. Esta cadeia produtiva é um dos principais itens da Balança Comercial Brasileira e exportou cerca de US $\$ 9,5$ bilhões em 2005, colocando o país na liderança mundial nas exportações do setor em valor (Abiove, 2011).

Do processamento dos grãos de soja, obtêm-se três produtos primários: $\mathrm{o}$ óleo degomado, o farelo de soja e a lecitina. Os demais produtos obtidos, como proteínas isoladas e concentradas, óleos refinados, gorduras, ácidos graxos, sabões entre outros, são derivados ou frações isoladas dos produtos primários, obtidos através do emprego de tecnologias específicas (Mendes, 2000).

Neste contexto, o refino do óleo de soja passa a ser um processo extremamente importante para agregar valor ao produto. Este processo pode ser definido como um conjunto de processo que visam transformar os óleos brutos em óleos comestíveis. A grande maioria dos óleos e gorduras destinados ao consumo humano é submetida ao refino, cuja finalidade é uma melhora na aparência, odor e sabor pela remoção do óleo bruto os componentes que caracterizam tais aspectos (Mandarino; Roessing, 2001).

\subsection{NEUTRALIZAÇÃO E LAVAGEM}

A finalidade da neutralização do óleo bruto é a eliminação de ácidos graxos livres em que se utilizam soluções alcalinas de soda cáustica ou, em casos raros, de carbonato de sódio. Os ácidos graxos neutralizados transformam-se em sabões e são separados dos glicerídeos pela diferença de peso específico.

Como as soluções aquosas tanto de soda cáustica como de sabão são insolúveis em óleo, o processo de neutralização se desenvolve entre as duas fases, a oleosa e a aquosa. Essa etapa merece atenção especial, pois pode ocorrer saponificação indesejável de triglicerídeos e consequente perda de material neutro, produzindo glicerol e uma mistura de sais alcalinos de ácidos graxos (sabões).

$\mathrm{O}$ processo básico para a neutralização do óleo de soja consiste em um aquecimento do óleo, pré-tratamento com ácido fosfórico $(85 \%$ de concentração) para possibilitar a eliminação dos fosfatídeos remanescentes, a neutralização com soda cáustica diluída (16 a $20^{\circ}$ Bé) e a separação dos sabões.

O valor comercial do óleo neutro é muito superior ao do sabão obtido com a neutralização dos ácidos graxos. Assim sendo, sob o ponto de vista econômico, é muito importante que no processo de neutralização se obtenha a maior quantidade possível do óleo neutro, isto é, que os ácidos graxos livres sejam neutralizados com a menos perda possível de óleo neutro (Rohr, 1978).

Após a neutralização, o óleo neutro possui ainda alto conteúdo de sabões que devem ser removidos (400 a 700 ppm de sabões). Dependendo do conteúdo residual de sabões requerido, um ou dois estágios de lavagem, são necessários.

O óleo proveniente da etapa de neutralização é misturado com 5 a $10 \%$ de água a uma temperatura mínima de $90^{\circ} \mathrm{C}$ e aquecido no trocador a placas até a temperatura de lavagem. A água de lavagem abrandada (máximo 6 graus ingleses de dureza) é dosada na linha de óleo através de sistema similar ao utilizado para o ácido/soda e vai ao misturador. $\mathrm{O}$ misturador envia a mistura óleo/água à centrífuga (Dorsa, 2000).

As centrífugas de lavagem separam o óleo como fase leve e a solução de sabão em água juntamente com insolúveis, como a fase pesada. Uma lavagem comumente remove $90 \%$ dos sabões (Norris, 1982). 


\subsection{LAVAGEM ÁCIDA COM RECIRCULAÇÃO}

O processo de lavagem ácida com recirculação consiste na reutilização da água descartada na etapa da lavagem do óleo, após prévio tratamento desta com ácido fosfórico, visando à recuperação do óleo arrastado e a redução no consumo de água. A água descarregada pela centrífuga lavadora é recolhida em um tanque de serviço, cuja finalidade é aumentar o volume de água em circulação, de forma tal a prolongar $o$ tempo de operação antes de saturar a água com impurezas contaminantes.

Deste tanque, a partir da adição de água quente, se restabelece o volume de água do sistema para renovar a água industrial. Através de uma bomba centrífuga, resistente a ataque de ácidos, a água acidulada é bombeada aos misturadores de lavagem. $\mathrm{Na}$ saída da bomba é instalado um controlador de $\mathrm{pH}$ que controla a dosagem de ácido. A água volta ao sistema com um $\mathrm{pH}$ constante e controlado da ordem de 5 .

Parte da água é descartada continuamente do tanque. Desta forma se vão retirando do sistema as impurezas separadas do óleo, junto com os sabões, como fósforo e metais pesados, para evitar a saturação da água com estes contaminantes. Durante este processo, há uma renovação em cerca de $20 \%$ da água industrial utilizada.

\section{MATERIAIS E MÉTODOS}

\subsection{MATERIAIS}

No presente trabalho, as matériasprimas utilizadas foram o óleo de soja e a de conhecer as correntes de interesse, realizou-se primeiramente um estudo do layout da refinaria de óleos. Elaborou-se um fluxograma simplificado do processo das principais linhas e realizou-se um balanço de massa para água e óleo nas etapas analisadas, no qual foram quantificados os principais fluxos.

A etapa de neutralização e lavagem conta com duas centrífugas de neutralização e três centrífugas de lavagem, dentre as quais, três apresentam água utilizada no sistema. Como forma

água de refrigeração de selos. Toda a água usada nos selos dos anéis das centrífugas e para lavar o óleo, deve ser branda e livre de metais (Duff, 1992).

Como a água é a principal matéria prima utilizada na lavagem do óleo, foi desenvolvido um fluxograma mais detalhado da distribuição desta pela planta (Figura 1).O primeiro tanque (tanque I) armazena água desmineralizada utilizada na hidratação do óleo bruto. Este tanque fornece a água que é utilizada atualmente em uma linha do processo de degomagem do óleo, na etapa de lavagem do óleo neutro e na diluição da soda cáustica utilizada na neutralização do óleo.

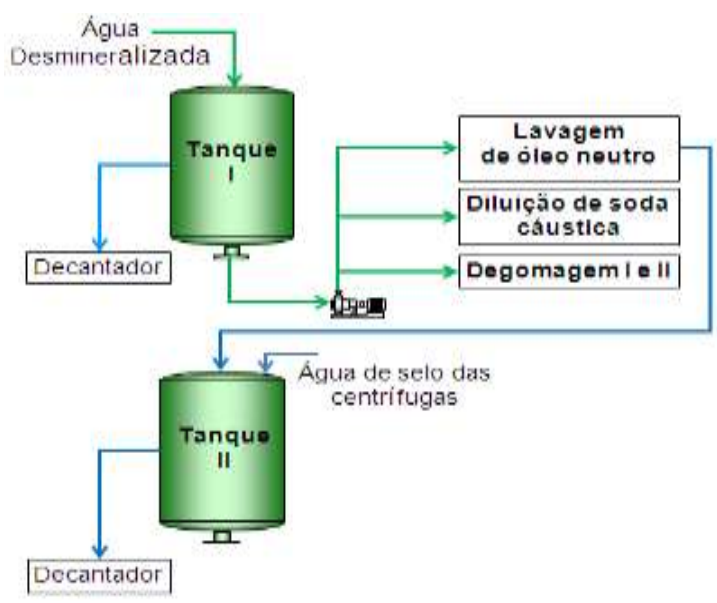

Figura 1.Distribuição de água na refinaria.

O tanque II recebe a água utilizada no resfriamento dos selos de carvão das centrífugas e a água descartada após lavagem do óleo neutro.

\subsection{MÉTODOS}

Para avaliar a viabilidade e assertividade do processo proposto, realizaram-se testes na planta. Inicialmente, eram coletadas amostras em condições normais de operação da água de lavagem na saída da centrífuga, na saída do tanque e na entrada e saída do decantador. $\mathrm{Na}$ corrente de entrada do tanque, foi introduzida uma tubulação com um dosador de ácido fosfórico. Com o pHmetro, controlava-se a vazão de ácido fosfórico dosado em função do $\mathrm{pH}$ da água descartada pelo tanque. $\mathrm{O} \mathrm{pH}$ utilizado foi de 4,5 - 5,5. Em seguida, realizava-se a lavagem com a água ENGEVISTA, V. 16, n. 3, p.384-391, Setembro 2014 
acidificada. Passadas de 1 a 2 horas para estabilização do processo eram coletadas novas amostras nas novas condições de operação e analisadas em laboratório o teor de óleo arrastado.

\section{RESULTADOS E DISCUSSÃO}

\subsection{ANÁLISE DO CONSUMO DE ÁGUA}

Foi possível quantificar o consumo de água no processo e o consumo esperado quando utilizado o processo de recirculação de água de lavagem por meio de um balanço de massa no sistema. Nesta etapa de cálculos, assumiu-se a densidade da água constante para todas as correntes, sendo o valor utilizado igual a $1000 \mathrm{~kg} / \mathrm{m}^{3}$.

Para o processo de degomagem, a dosagem de água corresponde a 3\% da vazão de óleo de soja que passa pela linha. Este parâmetro foi fixado a partir de análises do teor de gomas presente no óleo. A partir do balanço de massa realizado tem-se que a vazão de óleo bruto de soja é de $20000 \mathrm{~kg} / \mathrm{h}$ entrando na etapa da degomagem I e $5000 \mathrm{~kg} / \mathrm{h}$ na degomagem II.

$$
m_{\text {água }}^{0}=m_{\text {óleo }}^{0} * 0,03
$$

Por meio da Equação1, tem-se que a vazão de água consumida para a degomagem I é de $600 \mathrm{~kg} / \mathrm{h}$ e para a degomagem II de $150 \mathrm{~kg} / \mathrm{h}$.

$\mathrm{Na}$ etapa da neutralização, o consumo de água acontece em dois pontos do processo: na diluição da soda cáustica e na lavagem do óleo neutro. $\mathrm{O}$ cálculo para o consumo de água para diluição da soda cáustica é feita através da seguinte expressão (Dorsa, 2000):

$$
V_{g}=\frac{V_{S^{*}} d_{S^{* 0,5 *}}\left(100-C_{f}\right)}{C_{f}}
$$

De acordo com as condições operacionais estabelecidas, a concentração da soda diluída é de 14,83\% e utilizando-se a vazão de soda cáustica como sendo 107 l/h, obtém-se a partir da Equação 2 que a vazão de água de diluição é de 468,79 1/h.
Para o cálculo do volume de água utilizado na lavagem do óleo, utiliza-se a seguinte expressão (Dorsa, 2000):

$$
V_{l}=\frac{V_{m} * q_{1}}{87,3}
$$

Tomando a vazão total de óleo neutro como $20000 \mathrm{~kg} / \mathrm{h}$ de óleo e a partir da equação (3), para uma dosagem de água de $5 \%$ obtém-se que a vazão de água utilizada é de 1145,48 1/h.

A partir de dados de consumo de água desmineralizada da planta, é possível verificar que a vazão de água fornecida a refinaria encontra-se em cerca de $2.770,001 / \mathrm{h}$.

Realizando o balanço de massa global do tanque I, utilizando a Figura 1, conhecendo a vazão mássica de agua desmineralizada na entrada do tanque I e as vazões mássicas da agua para lavagem de óleo neutro, a agua para diluição de soda caustica e a água para degomagem, obtém-se que a vazão de água descarta para o decantador é de $405,73 \mathrm{~kg} / \mathrm{h}$.

A mesma análise foi realizada para o tanque de água II, onde as principais linhas de entrada de água são o descarte das centrífugas de lavagem e o descarte da água de refrigeração dos selos de carvão das centrífugas e o descarte para o decantador.

A água de selagem das centrífugas é fornecida diretamente da caldeira para a refinaria e após a refrigeração dos selos, esta é descartada no tanque II. Para quantificar o volume de água utilizado, foram realizados testes de vazão. Foi adotado um volume fixo de medida e eram realizadas tomadas de tempo. A partir do volume e do tempo, determinouse a vazão de água em cada centrífuga, totalizando uma vazão de $1822 \mathrm{~kg} / \mathrm{h}$.

Realizando o balanço e massa no tanque II, utilizando a Figura 1, determinou-se que o volume de água descartada para o decantador é de $2.967,48 \mathrm{~kg} / \mathrm{h}$.

Quantificando os fluxos das correntes de água no layout proposto, tem-se que o tanque I ficaria responsável pelo fornecimento da água de diluição da soda cáustica e a água para hidratação do óleo bruto (degomagem I e II), sendo este 
volume de 1218,79 1/h.A vazão de entrada do tanque II permaneceria inalterada, recebendo a água de lavagem e a água dos selos das centrífugas. Essa água proveniente dos selos seria responsável pela reposição da água de lavagem. O tanque II ficaria responsável por fornecer os $1145,48 \mathrm{l} / \mathrm{h}$ necessários para a lavagem e o restante seria descartado para o decantador.

Comparando as duas situações de processo, tem-se que a redução no consumo de água desmineralizada utilizada no processo sofreria uma redução de 2770 1/hpara aproximadamente $1250 \quad \mathrm{l} / \mathrm{h}$. Isso representa uma redução de cerca de 55\% no gasto de água desmineralizada.

Pode-se evidenciar ainda a redução no volume de efluente mandado para a estação de tratamento, que passaria de $3373,21 \mathrm{l} / \mathrm{h}$ para $1853,40 \mathrm{l} / \mathrm{h}$, ou seja, uma redução de aproximadamente 44,5\% no volume total.

\subsection{CONSUMO DE ÁCIDO FOSFÓRICO}

O objetivo dessas análises foi verificar qual o volume ideal a ser dosado no processo e qual o custo proveniente da operação.

A dosagem de ácido foi realizada através de uma bomba dosadora instalada próxima ao tanque de água. $\mathrm{O}$ ajuste da velocidade da bomba era realizado por meio de um inversor de frequência, através do qual era possível ajustar a vazão de ácido desejada.

Variou-se a vazão de ácido fosfórico dosada em cada ensaio a fim de verificar a influência da quantidade de ácido no teor de óleo arrastado. Utilizaram-se seis vazões de ácido diferentes, as quais foram escolhidas de acordo com o $\mathrm{pH}$ da água na entrada do processo de lavagem.

$\mathrm{O}$ ponto de dosagem do ácido fosfórico encontrava-se na saída do tanque II e o seu consumo foi determinado por meio de análises de consumo específico da planta, para verificar a coerência dos dados de consumo e gerar a curva de calibração da bomba.
As frequências escolhidas para os testes foram 30, 50, 70, 100, 125 e 150 RPM. Para cada uma dessas, mensurouse o consumo de ácido pela diferença de volume do tanque de ácido após 60 minutos de dosagem (Tabela 1).

Tabela 1. Quantificação da dosagem de ácido.

\begin{tabular}{cc}
\hline $\begin{array}{c}\text { Frequência } \\
\text { do inversor } \\
\text { (RPM) }\end{array}$ & $\begin{array}{c}\text { Dosagem no processo } \\
\mathbf{( l / h )}\end{array}$ \\
\hline 30 & 3,4 \\
50 & 3,3 \\
70 & 2,0 \\
100 & 4,0 \\
125 & 5,8 \\
150 & 9,0 \\
\hline
\end{tabular}

Conhecendo-se a vazão dosada em cada uma das frequências utilizadas, realizaram-se análises de arraste de óleo visando obter a condição ótima de operação. O ponto de coleta das amostras restringiu-se apenas ao descarte da centrífuga de lavagem, uma vez que a lavagem do óleo neutro é a etapa determinante do processo.

Para cada frequência escolhida, coletou-se uma amostra de água o determinou-se o teor de óleo arrastado, o pH na saída do tanque II e o pH na saída da centrífuga (Tabela 2).

Tabela 2.Valores do teor de óleo e pH da água na centrífuga de lavagem.

\begin{tabular}{cccc}
\hline $\begin{array}{c}\text { Frequência } \\
\text { (RPM) }\end{array}$ & $\begin{array}{c}\text { Teor } \\
\text { de } \\
\text { óleo } \\
(\%)\end{array}$ & $\begin{array}{c}\text { pH- } \\
\text { saída } \\
\text { tanque } \\
\text { II }\end{array}$ & $\begin{array}{c}\text { pH - saída } \\
\text { da } \\
\text { centrífuga }\end{array}$ \\
\hline 25 & 4,91 & 10,45 & 11,17 \\
50 & 3,28 & 7,98 & 10,78 \\
70 & 2,41 & 7,40 & 10,58 \\
100 & 0,45 & 6,60 & 7,19 \\
125 & 0,16 & 7,28 & 7,35 \\
150 & 0,01 & 1,12 & 2,63 \\
\hline
\end{tabular}

Com os resultados obtidos pode-se prever a quantidade de óleo arrastada na lavagem em diferentes vazões de ácido. De acordo com a literatura, o valor de $\mathrm{pH}$ ideal de operação do processo encontrase entre 4,5 e 5,5. Tomando esse critério como determinante e analisando os dados 
obtidos nos testes, assumiu-se que a frequência ideal de operação para a planta é 100 RPM.

\subsection{LAVAGEM ÁCIDA COM RECIRCULAÇÃO}

Os testes na planta possuem um caráter quantitativo, uma vez que as amostras retiradas foram analisadas em laboratório para verificar a assertividade da lavagem ácida. Com a planta operando em condição usual de lavagem, coletaram-se amostras em quatro pontos distintos da planta. Os pontos escolhidos foram na saída de centrífuga e lavagem, o descarte do tanque II, a entrada do decantador e a saída do decantador. Foi analisado o teor de óleo neutro arrastado na água e os resultados obtidos são apresentados na Tabela 3.

De acordo com os valores obtidos, pode-se verificar o elevado teor de óleo das amostras não acidificadas em todos os pontos coletados, dando maior destaque para a saída da centrifuga, onde se obteve uma média de aproximadamente $2,5 \%$ de óleo.

Analisando os resultados na saída do decantador, percebe-se a ineficiência do processo de separação e recuperação desse óleo arrastado. Uma vez que essa corrente é direcionada a estação de tratamento de efluente, não é possível realizar a recuperação desse óleo, evidenciando as perdas e a necessidade de um processo que reduza a quantidade de óleo arrastado.

Tabela 3.Teor de óleo nas amostras em condições normais de operação.

\begin{tabular}{cccc}
\hline Centrífuga & Tanque II & Entrada decantador & Saída decantador \\
\hline $2.88 \%$ & $0.45 \%$ & $1.02 \%$ & $0.51 \%$ \\
$1,89 \%$ & $1.10 \%$ & $2.03 \%$ & $1.72 \%$ \\
$1,52 \%$ & - & - & - \\
$1,32 \%$ & - & - & - \\
$7,52 \%$ & $1,05 \%$ & $0,81 \%$ & $0,66 \%$ \\
$4,51 \%$ & $1,20 \%$ & $1,25 \%$ & $1,26 \%$ \\
$3,22 \%$ & $0,73 \%$ & $0,65 \%$ & $0,84 \%$ \\
$1,55 \%$ & $1,01 \%$ & $2,70 \%$ & $2,75 \%$ \\
$0,66 \%$ & $0,42 \%$ & $0,66 \%$ & $1,39 \%$ \\
$3,10 \%$ & $1,19 \%$ & $1,94 \%$ & $0,75 \%$ \\
$4,72 \%$ & $2,79 \%$ & $1,96 \%$ & $1,70 \%$ \\
\hline
\end{tabular}

Com a nova bateria de testes, o sistema foi configurado para a realização da lavagem ácida com recirculação. Uma bomba dosadora de ácido fosfórico foi instalada próxima ao tanque II e realizouse a acidificação da água circulante do sistema. Aguardava-se um tempo aproximado de 60 minutos até a estabilização do processo e coletavam-se as amostras nos mesmo pontos das amostras anteriores (saída da centrífuga, saída do tanque II, entrada do decantador e saída do decantador). Os teores de óleo obtido após acidificação são apresentados na Tabela 4.

Analisando os novos resultados, é possível observar a significante redução nos teores de óleo arrastado na centrífuga após lavagem. Pode-se atribuir essa diminuição nos valores ao ácido presente na água, uma vez que esse neutraliza o excesso de soda presente na neutralização, minimizando a emulsificação entre as fases e facilitando a sua separação. Esse efeito estende-se aos demais pontos analisados, uma vez que o teor de óleo presente nessas amostras também reduziu.

\subsection{ANÁLISE ECONÔMICA}

Pelo balanço de massa realizado para a água na refinaria, tem-se que a vazão de água utilizada na lavagem do óleo neutro é de $1145 \mathrm{l} / \mathrm{h}$. O óleo arrastado na situação atual é 2,5\%, comum volume de óleo de $28,631 / \mathrm{h}$. Admitindo a densidade do óleo de soja como $0,92 \mathrm{~kg} / \mathrm{l}$, a massa de óleo descartada por arraste é de $26,34 \mathrm{~kg} / \mathrm{h}$. 
Tabela 4.Teor de óleo nas amostras da água acidificada.

\begin{tabular}{cccc}
\hline Centrífuga & Tanque II & Entrada decantador & Saída decantador \\
\hline $0,34 \%$ & $0,05 \%$ & $0,06 \%$ & $0,04 \%$ \\
$0,60 \%$ & $0,26 \%$ & $0,25 \%$ & $0,20 \%$ \\
$0,42 \%$ & - & - & - \\
$0,81 \%$ & - & - & - \\
$0,15 \%$ & $0,75 \%$ & $0,65 \%$ & $0,45 \%$ \\
$0,38 \%$ & $0,27 \%$ & $0,20 \%$ & $0,20 \%$ \\
$0,96 \%$ & $1,42 \%$ & $1,08 \%$ & $0,83 \%$ \\
$0,80 \%$ & $0,47 \%$ & $1,33 \%$ & $0,43 \%$ \\
$0,91 \%$ & $0,35 \%$ & $0,37 \%$ & $0,74 \%$ \\
$0,69 \%$ & $0,23 \%$ & $0,18 \%$ & $0,46 \%$ \\
$0,74 \%$ & $0,35 \%$ & $0,61 \%$ & $0,43 \%$ \\
$0,72 \%$ & $0,49 \%$ & $4,63 \%$ & $0,36 \%$ \\
$0,39 \%$ & $0,35 \%$ & $0,21 \%$ & $0,47 \%$ \\
$0,46 \%$ & $0,38 \%$ & $0,35 \%$ & $0,23 \%$ \\
$1,00 \%$ & $0,88 \%$ & $0,32 \%$ & $0,75 \%$ \\
$0,84 \%$ & $0,16 \%$ & $0,15 \%$ & $0,16 \%$ \\
$2,81 \%$ & $0,39 \%$ & $0,10 \%$ & $1,17 \%$ \\
$1,53 \%$ & $0,25 \%$ & $0,08 \%$ & $0,36 \%$ \\
\hline Para & & Atudmente & 0 \\
\hline
\end{tabular}

Para a nova configuração de operação, considerando que o teor de óleo diminuirá $0,45 \%$, tem-se um volume de óleo arrastado de $5,15 \mathrm{l} / \mathrm{h}$, ou ainda $4,74 \mathrm{~kg} / \mathrm{h}$. O valor do óleo de soja utilizado é de $\mathrm{R} \$ 1750,00$ a tonelada.

Entretanto, para verificar a viabilidade econômica do projeto, devese quantificar também o custo com o ácido fosfórico utilizado. Pelos resultados obtidos, tem-se que para a frequência ideal e trabalho (100 RPM), a vazão de ácido fosfórico utilizado é de 4,01/h. O valor comercial do ácido fosfórico encontra-se em torno de $\mathrm{R} \$ 2500,00$ por tonelada de ácido. Admitindo a densidade do ácido fosfórico como $1,684 \mathrm{~kg} / \mathrm{l}$, temse que a massa utilizada é de $6,736 \mathrm{~kg} / \mathrm{h}$. Logo o gasto financeiro para realização da lavagem ácida seria de $\mathrm{R} \$ 16,84 / \mathrm{h}$.

Atualmente, o volume de água fornecida a refinaria para os processos de degomagem, lavagem e diluição de soda cáustica, é de, em média, 2770 1/h. O custo de pré-tratamento dessa água é de $\mathrm{R} \$ 0,64 / \mathrm{m}^{3}$, segundo levantamento na empresa. Com a substituição do processo atual, o volume de água necessária para abastecer a refinaria seria de $1250 \mathrm{l} / \mathrm{h}$. O tratamento dos efluentes gerados pela refinaria tem um custo atual de $\mathrm{R} \$ 0,96 / \mathrm{m}^{3}$, segundo valores obtidos na empresa. Considerando como efluente as correntes descartadas para o decantador, o volume total gerado pelo processo atual é de $3373,21 \mathrm{l} / \mathrm{h}$ enquanto que pelo processo de lavagem ácida, o volume de efluente gerado é de 1853,40 1/h.

Fazendo um comparativo entre os custos totais dos dois processos, verificase a viabilidade econômica do projeto.

Tabela 5.Comparação entre os dois processos.

\begin{tabular}{ccccc}
\hline Processo & $\begin{array}{c}\text { Óleo } \\
(\mathbf{R} \mathbf{\$} / \mathbf{h})\end{array}$ & $\begin{array}{c}\text { Ácido fosfórico } \\
(\mathbf{R} \mathbf{\$} / \mathbf{h})\end{array}$ & $\begin{array}{c}\text { Água } \\
(\mathbf{R} \mathbf{\$} / \mathbf{h})\end{array}$ & $\begin{array}{c}\text { Efluente } \\
(\mathbf{R} \mathbf{\$} / \mathbf{h})\end{array}$ \\
\hline Sem lavagem ácida & 46,10 & - & 1,77 & 3,24 \\
Com lavagem ácida & 8,30 & 16,84 & 0,80 & 1,78 \\
Total & $+37,80$ & $-16,84$ & $+0,97$ & $+1,46$ \\
\hline Analisando os valores & obtidos, & $\mathbf{4 . ~ C O N C L U S A ̃ O ~}$ &
\end{tabular}

verifica-se que o projeto é economicamente favorável, pois pode gerar um retorno de aproximadamente $\mathrm{R} \$ 23,39$ por hora de operação da planta.
A partir do estudo realizado sobre a substituição do atual processo de lavagem pelo processo de lavagem ácida, pode-se verificar a assertividade do projeto em 
relação à redução do teor de óleo perdido por arraste nas centrífugas de lavagem. Utilizando-se apenas de água para a execução da etapa, o teor de óleo varia em torno de $2,5 \%$ enquanto que com a utilização da água acidificada este teor apresentou valores próximos a $0,45 \%$.

Observou-se também, através do balanço de massa realizado, a redução no consumo de água em cerca de 55\%, devido à reutilização da mesma no processo, assim como a redução em $44,5 \%$ na geração de efluentes. Essa redução é importante, uma vez que no cenário atual, com as novas legislações ambientais e o uso consciente da água tem se tornado uma preocupação frequente no meio industrial.

Com a melhoria no processo, irá gerarpara a empresa um retorno adicional de aproximadamente $R \$ 23,39$ por hora de operação, devido a recuperação do óleo arrastado na centrífuga.

\section{NOMENCLATURA}

$\mathrm{C}_{\mathrm{f}}$ :Concentração da soda diluída, \%;

$\mathrm{d}_{\mathrm{s}}$ :Densidade da soda bruta, considerado $1,5253 \mathrm{~kg} / \mathrm{l}$;

$\mathrm{q}_{1}$ :Dosagem de água de lavagem, \%;

$\mathrm{v}_{\mathrm{g}}$ :Vazão de água de diluição, $1 / \mathrm{h}$;

$\mathrm{v}_{\mathrm{l}}$ :Vazão de água de lavagem, $1 / \mathrm{h}$;

$\mathrm{v}_{\mathrm{m}}$ :Vazão de óleo neutro, $\mathrm{kg} / \mathrm{h}$;

$\mathrm{v}_{\mathrm{S}}$ :Vazão de soda cáustica, $1 / \mathrm{h}$.

\section{BIBLIOGRAFIA}

ABIOVE - Associação Brasileira das Indústrias de Óleos Vegetais.

DORSA, R. Tecnologia de Processamento de Óleos e Gorduras Vegetais e Derivados. $3^{\text {a }}$ Ed., 2000.

DUFF, H. G. Refining. In: WAN, P.J. Introduction to Fats and Oils Technology. $2^{a}$ Ed.,Champaign: AOCS Press, c.5: p.85-94, 1992.

MANDARINO, J. M. G.; ROESSING, A. C. Tecnologia para produção do óleo de soja: descrição das etapas, equipamentos, produtos e subprodutos. Londrina: Embrapa Soja, p. 40, 2001.
MENDES, A.C. Lecitina de Soja: processo de obtenção e refino. Porto Alegre: UFRGS. Monografia (Curso de Engenharia de Alimentos), Instituto de Ciência e Tecnologia de Alimentos, Universidade Federal do Rio Grande do Sul, 2000.

NORRIS, F. A. Refining and bleaching. In: SWARN, D. Bailey's industrial oil and fat products. $4^{\mathrm{a} E d}$., New York: John Wiley and Sons, v.2, c.4: p.253-314, 1982.

ROHR, R. Óleos e Gorduras Vegetais e seus Subprodutos Proteicos. $4^{\mathrm{a}}$ Ed., Campinas: Fundação Tropical de Pesquisas e Tecnologia, 1978. 